\title{
Implementasi Konsep Konservasi Air di Gedung Apartemen X
}

\author{
Vine Valenia David ${ }^{1 *}$, Kancitra Pharmawati ${ }^{2}$, Djoni Kusmulyana Usman ${ }^{3}$ \\ 1,2,3 Jurusan Teknik Lingkungan, Fakultas Teknik Sipil dan Perencanaan, \\ Institut Teknologi Nasional, Bandung \\ *Koresponden email: vinevaleniad123@gmail.com
}

Diterima: 12 Agustus 2019

Disetujui: 1 Oktober 2019

\begin{abstract}
Clean water crisis that occurred in Bandung is caused by land conversion in North Bandung area which is a recharge area into commercial buildings. This increases runoff rate from $40 \%$ to $70 \%$ that can lead can lead to flooding and reduced groundwater availability. Therefore, it is necessary to save water by implementing water conservation. Considering those problems, this study aims to apply the concept of water conservation in X Apartment building that is located in the North Bandung Region by referring to Mayor Regulation of Bandung in 2016. Water conservation efforts that will be applied are wastewater reuse into water recycle, rainwater harvesting, infiltration well construction and placing water meters. The application of water conservation concept considers two conditions, namely in rainy season and dry season. Total need for clean water can be saved by $45,8 \%$ in dry season, while in rainy season clean water can be saved by $31,74 \%$.
\end{abstract}

Keywords: water conservation, recycle water, rainwater harvesting, infiltration well, water meter

\begin{abstract}
Abstrak
Krisis air bersih yang terjadi di Kota Bandung diakibatkan oleh alih fungsi lahan di Kawasan Bandung Utara yang merupakan daerah resapan air menjadi bangunan-bangunan komersil. Hal tersebut memicu terjadinya peningkatan limpasan air permukaan dari $40 \%$ menjadi $70 \%$, sehingga dapat menimbulkan banjir dan ketersediaan air tanah berkurang. Maka, agar ketersediaan air tanah tetap terjaga perlu dilakukan penghematan air dengan menerapkan konservasi air. Mengingat permasalahan tersebut, penelitian ini bertujuan menerapkan konsep konservasi air di gedung Apartemen X yang berlokasi di Kawasan Bandung Utara dengan mengacu kepada Peraturan Wali Kota Bandung tahun 2016. Usaha konservasi air yang diaplikasikan yaitu pemanfaatan air limbah menjadi air daur ulang, pemanenan air hujan, pembangunan sumur resapan dan peletakan meter air. Penerapan konsep konservasi air ini mempertimbangkan dua kondisi yaitu musim hujan dan musim kemarau. Total kebutuhan air bersih dapat dihemat sebesar 54,22\% pada musim kemarau, sedangkan di musim hujan air bersih dapat dihemat sebesar $31,74 \%$.
\end{abstract}

Kata kunci : konservasi air, air daur ulang, pemanenan air hujan, sumur resapan, meter air

\section{Pendahuluan}

Kota Bandung sebagai salah satu kota metropolitan, memiliki aktivitas yang berpengaruh terhadap pendapatan ekonomi kota salah satunya dari sektor pariwisata. Berdasarkan BPS Kota Bandung (2018), sektor pariwisata memiliki kontribusi terbesar terhadap pendapatan ekonomi Kota Bandung yaitu sebesar $25,65 \%$.

Daya tarik yang dimiliki sektor pariwisata Kota Bandung, menimbulkan peningkatan jumlah pendatang yang mendorong peningkatan pembangunan hunian baru bagi para pendatang, salah satunya adalah apartemen. Apartemen X merupakan sebuah bangunan hunian bertingkat yang direncanakan berlokasi kawasan Bandung Utara dengan menempati luas tanah sebesar $3.140 \mathrm{~m}^{2}$ dan bangunan seluas $28.452 \mathrm{~m}^{2}$ yang terdiri dari 15 lantai. Pembangunan gedung apartemen tersebut, harus memperhatikan kualitas sarana dan prasarana gedung agar dapat memenuhi kebutuhan air bersih serta sistem sanitasi yang tersalurkan untuk seluruh penghuni gedung dengan adanya sistem plumbing (Noerbambang, 2005)

Lokasi perencanaan pembangunan Apartemen X yang terletak di Kawasan Bandung Utara tersebut, memiliki fungsi sebagai kawasan resapan air (RTRW Kota Bandung Tahun 2011 - 2031). Sebagai daerah resapan air, kawasan Bandung Utara berperan dalam menyimpan cadangan air, sehingga pembangunan yang mengakibatkan perubahan tata guna lahan wilayah tersebut, akan menimbulkan peningkatan limpa- 
san air saat terjadinya hujan. Selain itu, Peraturan Wali Kota Bandung No 1023 Tahun 2016 menyatakan bahwa bangunan gedung baru wajib menerapkan konsep bangunan hijau dengan aspek konservasi air.

Mengingat hal tersebut, maka pembangunan Apartemen X ini menerapkan konsep bangunan hijau dengan aspek konservasi air. Penerapan aspek konservasi air yang dilakukan yaitu dengan mengupayakan pemisahan sistem plambing air bersih dengan greywater dan blackwater, penggunaan meter air, pemanfaatan air hujan dengan rainwater harvesting, sumur resapan dan daur ulang air bekas agar ketersediaan air tanah tetap terjaga.

\section{Studi Literatur}

Studi literatur dilakukan dengan mengumpulkan teori pendukung yang relevan dari awal hingga akhir penelitian selain itu, meninjau pula standar serta peraturan yang digunakan. Adapun standard an peraturan yang menjadi acuan dalam penelitian ini yaitu Peraturan Wali Kota Bandung Nomor 1023 Tahun 2016 tentang Bangunan Gedung Hijau, SNI 03-7065-2005 tentang Tata Cara Perencanaan Sistem Plambing, dan Rencana Tata Ruang Wilayah Kota Bandung Tahun 2011-2031.

\subsection{Konservasi Air}

Konservasi air merupakan suatu usaha pengurangan pemakaian air atau pengingkatan pemanfaatan air (Kumari dan Singh, 2017). Sedangkan menurut Green Building Council Indonesia (2018), konservasi air adalah mengurangi pemakaian air bersih yang tidak diperlukan, meningkatkan sistem daur ulang serta pemakaian kembali air hujan ataupun air buangan. Konservasi air bertujuan untuk meningkatkan volume air dan efisiensi penggunaan air, serta memperbaiki kualitas air sesuai peruntukan, sehingga keterseediaan air terjaga serta meningkatkan suplai air. Penerapan konservasi air yang baik yaitu gabungan dari konservasi segi suplai air untuk pemakaian air kemudian hari dan konservasi segi kebutuhan yaitu efisiensi pemakaian air (Kodoatie dan Syarief, 2010)

Berdasarkan Peraturan Wali Kota Bandung Nomor 1023 Tahun 2016 tentang Bangunan Gedung Hijau penerapan konservasi air terdiri dari pemanfaatan air hujan, pemanfaatan air bekas, penggunaan saniter hemat air, perencanaan sumur resapan dan penggunaan meter air.

\subsection{Pemanfaatan Air Hujan}

Pemanfaatan air hujan dengan rainwater harvesting yang selanjutnya ditampung dalam tangki air baku lalu diolah ke IPA (Intalasi Pengolahan Air Bersih). Hasil pengolahan dimanfaatkan untuk konsumsi air primer (Peraturan Wali Kota Bandung, 2016).

\subsection{Pemanfaatan Air Bekas}

Pemanfaatan air bekas. Air buangan yang digunakan bersumber dari air buangan non kakus. Jenis air buangan ini ditampung dalam tangki penampungan kemudian diolah dengan instalasi pengolahan air buangan (wastewater treatment plant). Air buangan yang telah dilakukan pengolahan lalu disimpan di dalam tangki penampungan air daur ulang (recycle water tank) (Peraturan Wali Kota Bandung, 2016).

\subsection{Peralatan Saniter Hemat Air}

Penggunaan alat saniter hemat air berfungsi mengurangi pemakaian air berlebih (Green Building Council Indonesia, 2018).

\subsection{Sumur Resapan}

Sumur resapan merupakan resapan buatan untuk memberikan cadangan bagi air tanah akibat permukaan tanah yang ditutupi oleh gedung dan prasarananya. Sumur resapan merupakan bangunan yang berbentuk sumur yang memiliki fungsi dalam menampung aliran air permukaan dan menginfiltrasikannnya kedalam tanah. Air hujan yang tidak terinfiltrasi oleh tanah akan dialirkan menuju saluran drainase kota yang pembuangan akhirnya akan mengarah ke badan penerima (DAI, 2012).

Pembuatan sumur resapan bertujuan untuk mengendalikan banjir, mengurangi krisis air bersih, serta melindungi kesetimbangan air tanah (DAI, 2012).

\subsection{Meter Air}

Meter air digunakan untuk mengukur air yang digunakan, dengan meteran air, pengguna air dapat mengetahui apabila terjadi kebocoran pipa dan menghitung biaya penggunaan air. Peletakan meter air diletakan pada (Peraturan Wali Kota Bandung, 2016) :

a. Keluaran sumber air bersih yang berasal dari pipa service PDAM

b. Keluaran sumber air baku air tanah

c. Keluaran tangki penampungan air daur ulang (greywater) yang telah diolah oleh STP (Sewage Treatment Plant) 


\section{Metodologi Penelitian}

Penelitian ini diperoleh dari pengumpulan data-data sekunder yang sudah tersedia seperti denah lokasi perencanaan gedung, denah arsitek setiap lantai, fungsi ruang dan luas setiap lantai.

\subsection{Pengolahan Data dan Perencanaan Teknis}

\subsubsection{Perhitungan Jumlah Populasi}

Jumlah populasi gedung Apartemen $\mathrm{X}$ dihitung dengan menggunakan metode perbandingan luas bangunan efektif menggunakan persamaan berikut.

Jumlah Populasi $=\frac{\text { Luas efektif }(\%) \times \text { Luas lantai }\left(\mathbf{m}^{2}\right)}{\text { Standar beban hunian }\left(\mathbf{m}^{2} / \text { orang }\right)}$

\subsubsection{Perhitungan Kebutuhan Air Bersih}

Kebutuhan air bersih dalam gedung dihitung sesuai jumlah penghuni gedung dan standar pemakaian air bersih. Besar kebutuhan air bersih dalam satu hari dapat dihitung dengan menggunakan rumus di bawah ini (Noerbambang, 2005).

$\mathrm{Q}_{\mathrm{d}}=$ jumlah penghuni $\mathrm{x}$ standar pemakaian air

Standar kebutuhan air penghuni gedung yang digunakan yaitu berdasarkan SNI 03-7065-2005 tentang Tata Cara Perencanaan Sistem Plambing berdasarkan peruntukkan fungsi ruang seperti dalam Tabel 1. Pemakaian air untuk penggunaan gedung apartemen dilakukan pendekatan dengan rumah susun.

Tabel 1. Standar pemakaian air

\begin{tabular}{lcl}
\hline Penggunaan Gedung & Pemakaian Air & \multicolumn{1}{c}{ Satuan } \\
\hline Apartemen & 100 & Liter/penghuni/hari \\
Kantor & 50 & Liter/pegawai/hari \\
Gedung Serbaguna & 25 & Liter/kursi \\
Restoran & 15 & Liter/kursi \\
Peribadatan & 10 & Liter/jemaah \\
\hline \multicolumn{2}{c}{ Sumber : SNI 03-7065-2005 \& Noerbambang (2005) }
\end{tabular}

\subsubsection{Usaha Konservasi Air}

Usaha konservasi air bertujuan untuk mengetahui besaran air bersih yang berkurang oleh usaha pengurangan penggunaan sumber air utama primer PDAM dengan memanfaatkan kembali air bekas (greywater) untuk kebutuhan flushing dan rainwater harvesting. Besar usaha konservasi air ditentukan berdasarkan dua kondisi yaitu musim hujan dan musim kemarau. Usaha penghematan air musim hujan dapat dihitung dengan persamaan berikut.

Usaha konservasi air $=$ besar air daur ulang + pemanfaatan air hujan

Sehingga untuk mengetahui persentase usaha konservasi air ditentukan sebagai berikut.

Persentase $(\%)=\frac{\text { Usaha } \text { konservasi air }}{\text { Kebutuhan total air bersih }} \times 100 \%$

Sedangkan, pemanfaatan air hujan untuk menghitung besar usaha konservasi air pada musim kemarau dapat diasumsikan tidak ada pemanfaatan air hujan.

\subsubsection{Timbulan Air Limbah}

Berdasarkan perhitungan kebutuhan air bersih, maka akan diketahui timbulan air limbahnya. Air limbah dihasilkan sebesar $80 \%$ dari total kebutuhan air bersih. Terdapat dua jenis air limbah yaitu blackwater dan greywater. Blackwater yang dihasilkan dalam air limbah yaitu sebesar $25 \%$ sedangkan greywater sebesar $75 \%$. Penentuan debit air limbah dapat ditulis dalam persamaan berikut (Hardjosuprapto, 2000).

Q air limbah $=80 \% \times$ Total kebutuhan air bersih 


\subsubsection{Besar Daur Ulang Air Limbah}

Air daur ulang merupakan air bekas (greywater) yang telah diolah dalam Sewage Treatment Plant (STP). Seawage Treatment Plant (STP) adalah sistem pengolahan air limbah domestik menjadi air bersih kelas 2, yang dimanfaatkan untuk flushing, menyiram tanaman atau dibuang ke sungai tanpa mencemari air sungai (Topare dkk, 2019). Pada perencanaan ini, air hasil pengolahan STP dimanfaatkan sebagai sumber air sekunder keperluan flushing. Besar greywater yang dimanfaatkan sebagai daur ulang yaitu sebesar 75\% dari timbulan air limbah yang dihasilkan (Hardjosuprapto, 2000).

Jenis alat plambing yang memerlukan flushing untuk menggelontorkan kotoran yaitu water closet (WC) dan urinal. Besaran daur ulang air limbah ditentukan berdasarkan banyaknya penggunaan alat plambing setiap hari, kebutuhan air yang diperlukan setiap kali flushing dan jumlah populasi gedung, sehingga akan diperoleh jumlah air limbah yang di daur ulang dalam 1 hari. Penentuan besar kebutuhan flushing dihitung dengan persamaan berikut (Rinka, 2014).

Kebutuhan flushing = Kebutuhan air alat plambing (L/flush) x pemakaian alat plambing per hari.

Besarnya air daur ulang sama dengan total keperluan flushing populasi sehingga jumlahnya ditentukan sesuai persamaan berikut.

Besar daur ulang air limbah = kebutuhan flushing (L/flush) $\mathrm{x}$ banyak penggunaan (per hari) $\mathrm{x}$ jumlah populasi (orang)

\subsubsection{Rainwater Harvesting}

Salah satu pemanfaatan air hujan yaitu dengan cara pemanenan air hujan atau rainwater harvesting. Air hujan yang dipanen dalam sebuah tangki akan digunakan sebagai sumber air primer dalam sebuah penampungan air baku yaitu raw water tank. Raw water tank merupakan tangki yang berfungsi menampung air baku berasal dari air tanah dan air hujan Air baku tersebut digunakan untuk mengurangi kebutuhan air bersih dari PDAM pada musim penghujan. Pemanfaatan air hujan tersebut dimaksudkan sebagai upaya mengurangi beban sistem drainase kota oleh limpasan air hujan. 2016) :

Penentuan kapasitas raw water tank dapat dihitung sebagai berikut (Peraturan Wali Kota Bandung,

$\mathrm{V}$ raw water tank $=0,025 \mathrm{~m} \times$ luas lantai dasar $\left(\mathrm{m}^{2}\right)$

\subsubsection{Sumur Resapan}

Sumur resapan dibangun dengan tujuan menampung air hujan yang berasal dari atap dan air hujan yang jatuh ke tanah/site plan selanjutnya diresapkan kedalam tanah. Penentuan dimensi sumur resapan dapat dihitung dengan persamaan berdasarkan Peraturan Wali Kota Bandung Nomor 1023 Tahun 2016 berikut:

$$
\text { V sumur resapan }=0,025 \mathrm{~m} \text { x luas lantai dasar }\left(\mathrm{m}^{2}\right)
$$

\subsubsection{Peletakan Meter Air}

Penggunaan meter air berfungsi mengukur banyaknya air yang digunakan. Hasil pengukuran air oleh meter air dapat digunakan untuk menghitung biaya penggunaan air, mengontrol terjadinya kebocoran pipa (Green Building Council Indonesia, 2018). Mengacu kepada Peraturan Wali Kota Bandung Nomor 1023 Tahun 2016 tentang Bangunan Gedung Hijau, meter air dalam perencanaan ini akan diletakan di setiap inlet keluaran sumber air bersih primer (air tanah dan air PDAM saja) dan outlet sumber air bersih sekunder.

\section{Hasil dan Pembahasan}

\subsection{Kondisi Eksisting}

Gedung Apartemen X merupakan sebuah gedung bertingkat yang didalamnya terdiri dari tempat tempat hunian serta dilengkapi berbagai fasilitas - fasilitas pendukung. Apartemen $\mathrm{X}$ berlokasi di kawasan Bandung Utara dengan lahan seluas $3.140 \mathrm{~m}^{2}$ dengan luas bangunan sebesar $28.452 \mathrm{~m}^{2}$. Gedung ini hanya memiliki satu bangunan gedung saja.

Bangunan Apartemen X memiliki total 15 lantai. Fasilitas utama yaitu tempat hunian yang terdiri dari kamar tidur, dapur, toilet serta ruang tamu terletak pada lantai dua hingga 11. Sedangkan, fasilitas 
pendukung seperti minimarket, mushola, kantin, ruang bersama serbaguna, dan lainnnya berada di lantai basement dan ground floor.

Tipe unit apartemen ini merupakan kamar dengan tipe studio dan loft. Terdapat 2 tipe kamar studio yaitu kamar studio tipe 1 dan kamar studio tipe 2 pada setiap lantai di lantai dua sampai 11. Kamar studio tipe 1 terdiri dari 13 kamar Studio A, 7 kamar Studio B, 2 kamar Studio C Corner, 1 kamar Studio D Corner, 1 kamar Studio E Corner dan 1 kamar Studio F Corner yang memiliki fasilitas tempat tidur, toilet dan dapur. Kamar studio tipe 2 dengan fasilitas tempat tidur, toilet, dapur dan ruang tamu.

Perencanaan sistem pengaliran air bersih yang diterapkan pada gedung merupakan sistem tangki atap. Kebutuhan air bersih yang diperlukan oleh gedung berasal dari dua sumber yaitu sumber air primer dan sumber air sekunder.

Sumber air bersih primer yang digunakan untuk aktivitas domestik seperti mandi, mencuci, memasak dan lainnya berasal dari PDAM sebagai sumber air utama dan air tanah juga air hujan hasil pemanenan sebagai sumber air cadangan.

Air bersih PDAM ditampung didalam ground water tank (GWT). Sedangkan sumber air cadangan ditampung didalam tangki raw water tank namun sumber air ini akan dialirkan menuju GWT apabila diperlukan. Air bersih yang dalam GWT akan dialirkan menuju roof tank (RT) dengan bantuan pompa. Alat plambing yang dialirkan oleh sumber air primer yaitu jet spray, shower, lavatory, kitchen sink dan faucet. Selain itu, sistem penyediaan air bersih gedung terdapat sumber air bersih lain yaitu sumber air sekunder yang merupakan air hasil olahan STP (Sewage Treatment Plant) yang berasal dari greywater bersumber dari kitchen sink, floor drain dan lavatory. Air bersih sekunder ditampung kedalam tangki air daur ulang setelah diolah di STP.

STP untuk mengolah air limbah yang diterapkan yaitu STP dengan teknologi biotech. Pengolahan air limbah dalam STP ini memanfaatkan sistem pengolahan aerob dan anaerob sehingga air limbah dapat diolah menjadi air bersih. Selain itu STP biotech dapat membunuh bakteri patogen yang terkandung dalam air limbah karena memiliki sistem desinfeksi (Fibertek, 2016). Hasil olahan STP dimanfaatkan kembali untuk keperluan flushing alat plambing water closet dan urinal. Sedangkan air kotor (blackwater) yang dihasilkan dari alat plambing water closet dan urinal disalurkan dan diolah dalam tangki septik.

Pada pengaliran air hujan di gedung Apartemen X, air hujan yang jatuh ke atap gedung perencanaan disalurkan melalui talang air hujan dan pipa tegak, selanjutnya, air hujan ditampung ke dalam tangki air baku, lalu disalurkan menuju ground water tank (GWT) setelah diolah pada water treatment plant (WTP) untuk dimanfaatkan sebagai sumber air primer.

Apabila air hujan yang ditampung dalam tangki air baku berlebih, maka akan disalurkan menuju sumur resapan. Selain itu, sumur resapan juga akan menangkap air hujan yang jatuh pada site plan gedung perencanaan. Skema perencanaan penerapan konservasi air di Apartemen X dapat dilihat pada Gambar 1 .

\subsection{Perhitungan Jumlah Populasi}

Perkiraan jumlah populasi dihitung untuk memperoleh besar kebutuhan air bersih penghuni keseluruhan gedung dengan persamaan 2. Sedangkan jumlah populasi dihitung dengan menggunakan persamaan 1. Persentase untuk menentukan banyaknya pria dan wanita dari jumlah populasi mengacu pada BPS Kota Bandung (2018) yaitu pria sebesar 50,4\% dan wanita sebesar 49,6\%. Jumlah populasi gedung ditunjukan dalam Tabel 2.

Tabel 2. Jumlah populasi gedung

\begin{tabular}{lc}
\hline \multicolumn{1}{c}{ Populasi } & Jumlah Populasi (orang) \\
\hline Penghuni & 870 \\
Tamu & 204 \\
Pegawai & 26 \\
\hline Total & 1.100 \\
\hline
\end{tabular}

Sumber: Hasil pengolahan data (2019)

Jumlah populasi gedung Apartemen X yaitu sebanyak 1.100 orang dengan jumlah penghuni 870 orang, tamu 204 orang dan pegawai 26 orang.

\subsection{Perhitungan Kebutuhan Air}

Kebutuhan air bersih dalam gedung ditentukan berdasarkan populasi penghuni setiap lantai dengan menggunakan standar kebutuhan air per orang per hari berdasarkan fungsi ruangan setiap lantai (Persamaan 1). Kebutuhan air bersih populasi dapat dilihat dalam Tabel 3. 
Tabel 3. Kebutuhan air bersih

\begin{tabular}{lc}
\hline \multicolumn{1}{c}{ Populasi } & Kebutuhan Air (L/hari) \\
\hline Penghuni & 87.000 \\
Tamu & 4.588 \\
Pegawai & $2.115,17$ \\
\hline Total & $93.703,16$ \\
\hline \multicolumn{2}{c}{ Sumber: Hasil pengolahan data (2019) }
\end{tabular}

Berdasarkan hasil perhitungan, jumlah kebutuhan air bersih keseluruhan untuk Gedung Apartemen X sebesar 93.703,16 L/hari.

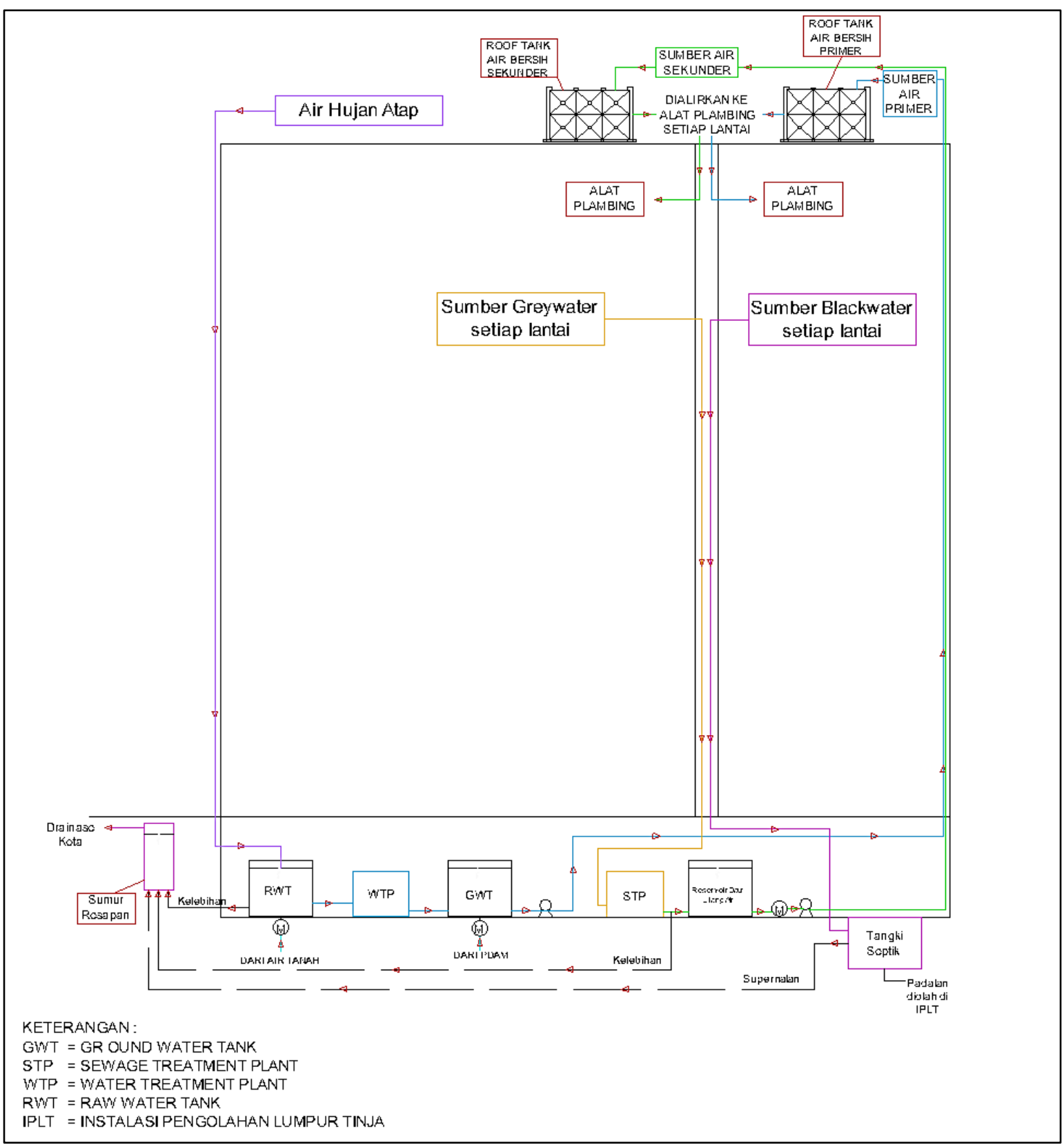

Gambar 1. Skema penerapan konservasi air

\subsection{Timbulan Air Limbah}

Aktifitas domestik dari gedung perencanaan menghasilkan air limbah sebesar $80 \%$ dari total kebutuhan air bersih. Blackwater yang dihasilkan dalam air limbah yaitu sebesar $25 \%$ sedangkan greywater menghasilkan 75\% (Hardjosuprapto, 2000). Penentuan besar air limbah dapat dihitung menggunakan persamaan 5. Berikut hasil rekapitulasi timbulan air limbah di gedung Apartemen X yang ditunjukan dalam Tabel 4 
Tabel 4. Rekapitulasi timbulan air limbah

\begin{tabular}{lc}
\hline \multicolumn{1}{c}{ Air Limbah } & Timbulan (L/hari) \\
\hline Greywater & $56.221,90$ \\
Blackwater & $18.740,63$ \\
\hline Total Air Limbah & $74.962,53$ \\
\hline \multicolumn{2}{c}{ Sumber: Hasil pengolahan data (2019) }
\end{tabular}

Dari hasil perhitungan, diperoleh timbulan air limbah yaitu 74.962,53 L/hari dengan timbulan greywater sebesar 56.221,90 dan timbulan blackwater sebesar 18.740,63 L/hari.

\subsection{Perhitungan Besar Daur Ulang Air Limbah}

Besar air daur ulang limbah harian ditentukan berdasarkan besaran air yang digunakan setiap kali flushing WC dan urinal serta banyakanya pemakaian WC dan urinal dalam sehari oleh penghuni gedung. Jumlah air limbah yang didaur ulang akan sama dengan jumlah air yang diperlukan oleh penghuni untuk keperluan flushing.

Kebutuhan air tiap pemakaian merupakan kebutuhan air yang digunakan oleh alat plambing water closet (WC) dan urinal setiap kali flush. Jumlah air yang digunakan WC untuk sekali flush yaitu sebanyak 6 L/flush sedangkan urinal memerlukan air sebanyak 4 L/flush (Green Building Council Indonesia, 2018). Penggunaan WC dan urinal dalam sehari juga memengaruhi besarnya daur ulang air limbah. Kebutuhan air alat plambing dapat dilihat pada Tabel 5. Sedangkan pemakaian WC dan urinal dalam satu hari ditunjukan dalam Tabel 6.

Tabel 5. Kebutuhan air alat plambing

\begin{tabular}{clc}
\hline No & Jenis Alat Plambing & $\begin{array}{c}\text { Kebutuhan air } \\
\text { (L/flush) }\end{array}$ \\
\hline 1 & Water closet (WC) & 6 \\
2 & Urinal & 4 \\
\hline \multicolumn{3}{l}{ Sumber : Green Building Council Indonesia (2018) }
\end{tabular}

Tabel 6. Pemakaian WC dan urinal dalam satu hari

\begin{tabular}{clcc}
\hline \multirow{2}{*}{ No } & \multicolumn{2}{c}{ Populasi } & \multicolumn{2}{c}{ Banyaknya penggunaan (kali per hari) } \\
\cline { 3 - 4 } & & WC & Urinal \\
\hline 1 & Penghuni & 5 & - \\
2 & Pegawai & 4 & 2 \\
3 & Tamu & 2 & 2 \\
\hline \multicolumn{2}{r}{ Sumber : Dietemann dkk., (2002) \& Efficiency. A.f.W (2008) }
\end{tabular}

Berdasarkan Tabel 5 dan Tabel 6, maka banyak kebutuhan flushing penghuni gedung dalam sehari dan besar air daur ulang limbah dapat ditentukan menggunakan persamaan 6 dan persamaan 7. Berikut hasil perhitungan kebutuhan flushing dan besar air daur ulang di gedung Apartemen X pada Tabel 7 dan Tabel 8.

Tabel 7. Kebutuhan Flushing

\begin{tabular}{lcccc}
\hline Populasi & $\begin{array}{c}\text { Jenis Alat } \\
\text { Plambing }\end{array}$ & $\begin{array}{c}\text { Kebutuhan } \\
\text { Air tiap } \\
\text { Pemakaian( } \\
\text { L/hari) }\end{array}$ & $\begin{array}{c}\text { Banyak } \\
\text { Penggunaan (kali } \\
\text { per hari) }\end{array}$ & $\begin{array}{c}\text { Kebutuhan } \\
\text { Flushing } \\
\text { (L/flush) }\end{array}$ \\
\hline Penghuni & WC & 6 & 5 & 30 \\
Tamu & WC & 6 & 2 & 12 \\
Pegawai & Urinal & 4 & 2 & 8 \\
& WC & 6 & 4 & 24 \\
\hline
\end{tabular}

Sumber: Hasil pengolahan data (2019) 
Tabel 8. Besar air daur ulang

\begin{tabular}{lcccc}
\hline \multirow{3}{*}{ Populasi } & $\begin{array}{c}\text { Jenis } \\
\text { Alat } \\
\text { Plambing }\end{array}$ & $\begin{array}{c}\text { Jumlah } \\
\text { Populasi } \\
\text { (orang) }\end{array}$ & $\begin{array}{c}\text { Kebutuhan } \\
\text { Flushing }\end{array}$ & $\begin{array}{c}\text { Kebutuhan Air Daur Ulang } \\
\text { (L/hari) }\end{array}$ \\
\hline Penghuni & WC & 870 & 30 & 26.100 \\
Tamu & WC & 204 & 12 & $1.693,93$ \\
& Urinal & & 8 & $1.129,28$ \\
Pegawai & WC & 26 & 24 & 612,38 \\
& Urinal & 8 & 204,13 \\
\hline Total & \multicolumn{4}{c}{ 1.100 } \\
\hline \multicolumn{5}{c}{ Sumber: Hasil pengolahan data (2019) }
\end{tabular}

Jadi, besar air limbah yang dilakukan daur ulang yaitu 29.739,72 L/hari.

\subsection{Rainwater Harvesting}

Upaya konservasi lain yang diterapkan selain daur ulang air yaitu pemanfaatan air hujan. Pemanfaatan air hujan dilakukan dengan menangkap air hujan oleh catchment area pada atap lalu air hujan dialirkan dari talang menuju ke pipa tegak air hujan yang akan mengarah pada raw water tank atau tangki air baku. Raw water tank menampung sumber air bersih primer yang berasal dari air hujan dan air tanah.

Pada musim hujan, pemanfaatan air hujan diutamakan dibandingkan dengan air tanah untuk mengurangi pemakaian air bersih PDAM. Sedangkan, di musim kemarau, air bersih yang berasal dari PDAM digunakan sebagai sumber air utama. Kapasitas raw water tank sumber air bersih sekunder dihitung berdasarkan persamaan 8 , sehingga diperoleh kapasitas raw water tank sebesar 21,35 $\mathrm{m}^{3}$ untuk menampung air hujan dan air tanah.

Apabila air hujan berlebih sehingga tidak dapat ditampung dalam raw water tank lagi, maka kelebihan air hujan akan disalurkan menuju sumur resapan.

\subsection{Sumur Resapan}

Sumur resapan pada gedung Apartemen X direncanakan akan menampung air larian permukaan yang berasal site plan, supernatan dari tangki septik, air berlebih yang ditampung dalam raw water tank, juga air hasil pengolahan STP yang berlebih dan tidak digunakan sebagai konsumsi air bersih sekuder.

Kapasitas sumur resapan ditentukan menggunakan persamaan 9 sesuai Peraturan Wali Kota Bandung Nomor 1023 Tahun 2016 tentang Bangunan Gedung Hijau maka volume sumur resapan yang dibangun yaitu $21,35 \mathrm{~m}^{3}$.

\subsection{Peletakan Meter Air}

Meter air adalah alat yang berfungsi mengukur besarnya aliran air yang mengalir. Pemasangan meter air bertujuan mendeteksi kebocoran air, serta menghitung biaya pemakaian air (Green Building Council Indonesia, 2018).

Pemasangan meter air pada gedung Apartemen X mengacu kepada Peraturan Wali Kota Bandung Nomor 1023 Tahun 2016 tentang Bangunan Gedung Hijau, meter air akan diletakan pada beberapa tempat sebagai berikut :

1. Keluaran sumber air bersih yang berasal dari pipa service PDAM sebeleum ditampung kedalam tangki penampungan air bersih yang akan didistribusikan ke setiap alat plambing sebagai air bersih primer

2. Keluaran sumber air baku air tanah sebelum ditampung kedalam tangki penampungan air baku

3. Keluaran tangki penampungan air daur ulang (greywater) yang telah diolah oleh STP (Sewage Treatment Plant) dan akan digunakan sebagai air bersih sekunder untuk keperluan flushing

\subsection{Usaha Konservasi Air}

Konservasi air di gedung Apartemen X yang diterapkan diantaranya pemanfaatan air limbah menjadi air daur ulang, pemanfaatan air hujan, pembangunan sumur resapan serta pemasangan meter air. Penerapan usaha konservasi air oleh pemanfaatan air limbah menjadi air daur ulang dan pemanfaatan air hujan berpengaruh dalam mengurangi penggunaan sumber air bersih PDAM gedung perencanaan. Usaha konservasi air dapat dihitung berdasarkan kebutuhan total air bersih gedung yaitu sebanyak 93.703,16 L/hari (lihat Tabel 3) dan besar air daur ulang sebanyak 29.739,72 L/hari (lihat Tabel 8).

Usaha konservasi air ditentukan berdasarkan dua kondisi, yaitu musim hujan dan musim kemarau. Penentuan dua kondisi tersebut dilakukan karena mempertimbangkan besaran pemanfaatan air hujan pada musim hujan dan musim kemarau. Besarnya air bersih yang berkurang dengan menerapkan usaha kon- 
servasi air dapat dihitung menggunakan persamaan 3 dan persamaan 4. Hasil rekapitulasi perhitungan usaha konservasi air ditunjukan dalam Tabel 9 berikut.

Tabel 9. Rekapitulasi usaha konservasi air

\begin{tabular}{ccc}
\hline Kondisi & $\begin{array}{c}\text { Penghematan Air } \\
\text { (L/hari) }\end{array}$ & $\begin{array}{c}\text { Persentase } \\
(\%)\end{array}$ \\
\hline Musim Hujan & $51.089,72$ & 54,22 \\
Musim Kemarau & $29.739,72$ & 31,74 \\
\hline
\end{tabular}

Sumber: Hasil pengolahan data (2019)

Pada kondisi musim hujan, pemanfaatan air hujan sebesar $21.350 \mathrm{~L} /$ hari diasumsikan memenuhi raw water tank sehingga besar usaha konservasi air yaitu 51.089,72 L/hari dengan persentase sebesar $54,22 \%$. Sedangkan pada musim kemarau, diasumsikan tidak terjadi hujan dan hanya menggunakan air PDAM sebagai sumber air bersih primer utama maka besar usaha konservasi air yaitu 29.739,72 L/hari dengan persentase sebesar $31,74 \%$.

\section{Kesimpulan}

Penerapan konservasi air di gedung Apartemen X dapat menghemat air baik di musim kemarau maupun di musim hujan. Pada musim kemarau air akan dihemat sebanyak 51.089,72 L/hari dengan persentase sebesar $54,22 \%$ sedangkan pada musim hujan air dapat dihemat sebanyak $29.748,46$ L/hari dengan persentase sebesar $31,75 \%$.

\section{Referensi}

BPS Kota Bandung. (2018). Bandung dalam Angka 2018. Badan Pusat Statistik Kota Bandung.

DAI. (2012). Sumur Resapan Sebuah Adpatasi Perubahan Iklim dan Konservasi Sumberdaya Air. USAID Indonesia: USAID Indonesia Urban Water Sanitation and Hygiene

Diatemann, A., Goodman, J., Gregg, T., dan Nelson, J. (2002). Overview of Retrofit Strategies-A Guide for Apartment Owners and Managers. San Fransisco: Water Resouurces Engineering, Inc.

Efficiency, A.f.Wp. (2008). Commercial Restroom Water Audits

Fibertek, P. S. U. (2016). IPAL-STP BioRich. Diunduh dari suryautamafibertek.co.id

Green Building Council Indonesia. 2018. Naskah Guidelines Green Building Council Indonesia. Diunduh dari gbcindonesia.org.

Hardjosuprapto, M. M. (2000). Penyaluran Air Buangan. Bandung: Institut Teknologi Bandung.

Kodoatie, R. J., dan Syarief, R. (2010). Tata Ruang Air. Yogyakarta: C.V ANDI OFFSET.

Kumari, M., dan Singh, J. (2017). Water Conservation: Startegies and Solutions. International Journal of Advanced Research and Review, 1(4), 75-79.

Noerbambang, S.M., dan Morimura, T. (2005). Perencanaan dan Pemeliharaan Sistem Plambing. Jakarta: Pradnya Paramita.

Peraturan Wali Kota Bandung Nomor 1023 Tahun 2016 tentang Bangunan Gedung Hijau.

RTRW Kota Bandung tahun 2011 -2013.

Rinka, D.Y. (2014). Perencanaan Sistem Plambing Air Limbah dengan Penerapan Konsep Green Building pada Gedung Panghegar Resort Dago Golf-Hotel\&Spa. Jurnal Reka Lingkungan.

SNI 03-7065-2005 tentang Tata Cara Perencanaan Sistem Plambing.

Topare, N., J Attar, S., dan M Manfe, M. (2019). Sewage/Wastewater Treatment Technologies : A Review. 